\title{
Vicisitudes y coyunturas del audiovisual iberoamericano
}

Carlos A. López Piñeiro*

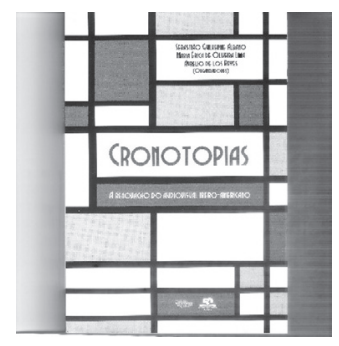

ALBANO, Sebastião Guilherme; LIMA, Maria Érica de Oliveira; REYES, Aurelio de lós (Coordinadores). Cronotopias. A renovação do audiovisual iberoamericano. Natal: EDUFRN, 2012

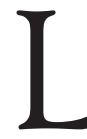

ibro editado en Natal (Río Grande do Norte, Brasil) que presenta una serie de trabajos sobre el cine iberoamericano restringidos casi en exclusiva a tres Estados (Argentina, Brasil y México) y una Comunidad Autónoma (Galicia, España). Dado que la edición se produjo, como manifiestan las presentaciones, en el contexto de la conmemoración del Año de Brasil en Portugal y viceversa, se podría echar en falta, al menos, un trabajo específico sobre el cine luso. Junto a esa delimitación de contenidos respecto a la amplitud del ámbito espacial enunciado en el título, el libro presenta una cierta diversidad respecto al ámbito temporal abarcado por los textos, pese a que la intención inicial declarada en la Presentación era la de ceñirse a la evolución - definida como renovación - de los últimos veinte años. Por otra parte también se da una plural y enriquecedora divergencia de enfoques estilísticos, ya que unos trabajos son eminentemente

\footnotetext{
* Guionista, productor y director cinematográfico. Historiador del Cine. Fue profesor en la EGACI (Escola Galega de Cine) y en la UdV (Universidad de Vigo). Miembro de la AGAG (Asociación Galega de Guionistas).

E-mail: amoros@uvigo.es
} 
ensayísticos al referirse a la evolución de contenidos y estéticas, mientras que otros son eminentemente analíticos al referirse a la evolución de la producción. Dentro de este carácter diverso de la edición se sitúa también el hecho de que en ella se alternen textos en portugués con otros en español, todos con aportaciones destacables.

Vistos uno a uno, el trabajo Gestos e afetos fugazes, de Denilson Lopes, comenta contenidos y estéticas de ciertos filmes brasileños que relaciona con otros estadounidenses, europeos o asiáticos, emparentados por la ocasionalidad y fugacidad de los encuentros amorosos que en ellos se narran.

El capítulo Hacia la desaparición de la industria cinematográfica en México (1950-2010), de Aurelio de los Reyes, describe analíticamente la evolución global de esta producción así como los principales temas tratados. Entre otros hechos señala que los sindicatos la convirtieron en un coto cerrado hasta que a principios de los 70 se crearon empresas estatales que dieron oportunidades a jóvenes procedentes de facultades y escuelas, quienes aportaron un cine de calidad, pero que la distribución y exhibición siguieron en manos estadounidenses.

En cuanto a Martin Rejman no contexto do último novo cinema argentino, de Ángela Prysthon, se centra en describir la evolución temática, estética y de contenidos del cine realizado en las dos últimas décadas en Argentina por jóvenes directores. Señala que estos, rompiendo con la tradición del cine alegórico sobre temas políticos y morales, eligieron temas cotidianos para tratarlos con técnicas de documental, aunque algunos optaron por conjugar ambos estilos.

El texto Novas consonâncias entre a televiçao e o cinema: apanágios do regionalismo mediático, de María Érica de Oliveira Lima, analiza dentro del marco de una confrontación sociocultural entre el Nordeste y el Sudeste de Brasil, la evolución del cine en el Estado de Pernambuco y la tipología de la programación televisiva de las cadenas del Estado de Ceará, especificando la implicación de estas en la producción y difusión de los filmes allí realizados. Finalmente comenta un programa de TV Diário, "Cine Nordeste", 
concebido como un cine-forum dedicado la producción cinematográfica de la región.

La disertación sobre la Conjuntura crítica do audiovisual latino-americano, de Sebastiao Guilherme Albano, efectúa una interpretación de los filmes de las dos últimas décadas bajo la influencia de una unidad identitaria cuyas circunstancias sociopolíticas y culturales se trasladan tanto a los modos de producción, distribución y exhibición, como a los contenidos y estéticas, enmarcados en un modelo denominado "poética da responsabilidade".

El capítulo Al margen del orden: apuntes sobre bandoleros en el cine y otros temas, de Silvia Oróz, incide en la mitología popular del bandolero como una temática popular que llega al cine argentino procedente de la narrativa oral.

Y, finalmente, el estudio sobre Cine Gallego: origen y evolución. Situación y tendencias en el siglo XXI, de Anna Amorós Pons, ofrece una síntesis de la historia del cine en Galicia en cinco etapas, situando como marco de la última de ellas el asiento de la democracia en una España estructurada en comunidades autónomas que da origen a la Televisión de Galicia. La investigación se centra en la evolución de la producción en la primera década del presente siglo, cuantificando con el apoyo de gráficos la realizada para su explotación en salas de cine y para televisión, la de filmes de animación y la clasificación por géneros.

A mi entender es acertada la catalogación de la cinematografía gallega como subalterna de la española, tal y como aparece reflejado en la Introducción del libro, porque en su mayoría no tiene como idioma original el gallego ni se debe a autores gallegos. Pese al apoyo de instituciones y entidades de la administración autónoma (Xunta de Galicia), cuya existencia política se basa y justifica estatutariamente en la diferencia cultural e idiomática del país al que representa, se impuso un cine de raíz sucursalista. 